Check for updates

Cite this: RSC Adv., 2018, 8, 37573

Received 28th September 2018 Accepted 26th October 2018

DOI: $10.1039 / \mathrm{c} 8 \mathrm{ra0} 0047 \mathrm{j}$

rsc.li/rsc-advances

\section{Phytotoxicity and anti-phytopathogenic activities of marine-derived fungi and their secondary metabolites $\dagger$}

\author{
Rui-Huan Huang,,$^{\mathrm{a}}$ Jian-Yu Gou,,$^{\mathrm{b}}$ Dong-Lin Zhao, (D) *a Dan Wang, ${ }^{a}$ Jing Liu, ${ }^{\mathrm{b}}$ \\ Guo-Yong Ma, ${ }^{b}$ Yi-Qiang Li and Cheng-Sheng Zhang*a
}

To find new pesticides for agricultural use, 133 fungal strains were isolated from coastal marine habitats, from which 37 independent isolates were identified, belonging to 20 genera in nine orders, and the diversity of the isolated fungi were discussed. The phytotoxicity and anti-phytopathogenic fungal and bacterial activities of these 37 extracts, and two previously isolated fungal extracts were evaluated, displaying different levels of bioactivity. Based on the bioactive and chemical screening, an Alternaria sp. (P8) strain, which showed prominent bioactivity and contained abundant secondary metabolites was selected for further chemical investigation; one new compound, a benzopyranone (1), and seven known compounds (2-8) were obtained. Their structures were determined by analysing extensive NMR spectroscopic data and ECD comparisons. Compounds 1, 2, and 6-8 showed obvious phytotoxicity, especially against amaranth, and compound 1 also showed potent antifungal activity toward Alternaria brassicicola. To the best of our knowledge, this is the first report of the phytotoxicity of marine-derived fungi and their secondary metabolites. These studies should provide the foundation for future research into the use of such fungal extracts to combat weeds and diseases in agriculture.

\section{Introduction}

It has been estimated that at least $10 \%$ of global food production is lost to plant diseases; among these, weeds, plant pathogenic fungi, and bacteria are three major pests causing drastic loss in yield. ${ }^{1}$ Conventional chemicals have brought many benefits to mankind in the agricultural area, but their toxicity to both humans and animals has always been a concern. ${ }^{2}$ Therefore, new pesticides with high efficacy and safety need to be discovered and developed to replace the conventional ones. ${ }^{3}$

Natural products (NPs) play an important role in the search for new pesticides. According to the literature, NPs accounted for the majority $(35.7 \%)$ of new active ingredient registrations

${ }^{a}$ Marine Agriculture Research Center, Tobacco Research Institute of Chinese Academy of Agricultural Sciences, Qingdao 266101, China. E-mail: zhaodonglin@caas.cn; zhchengsheng@126.com; Tel: +86-532-8870-2115

${ }^{b}$ Zunyi Branch, Guizhou Tobacco Company, Zunyi 563000, China

$\dagger$ Electronic supplementary information (ESI) available: Table S1: Identification and phylogenetic affiliations of the isolated marine-derived fungal strains, Table S2: antifungal activity against spore germination of the marine-derived fungal extracts $\left(10.0 \mathrm{mg} \mathrm{mL}^{-1}\right)$, Table S3: antifungal activity against mycelial growth $\left(10.0 \mathrm{mg} \mathrm{mL}^{-1}\right)$ of plant pathogenic fungi, Table S4. Antibacterial activity of the marine-derived fungal extracts, Fig. S1: the sources of the isolate marine-derived fungal strains, Fig. S2-S8: ${ }^{1} \mathrm{H}$ NMR, ${ }^{13} \mathrm{C}$ NMR, COSY, HMQC, HMBC, 1D NOE, and HRESIMS spectra of compound 1. See DOI: $10.1039 / \mathrm{c} 8 \mathrm{ra0} 0047 \mathrm{j}$

\$ Co-first authors. with the Environmental Protection Agency (EPA) from 1997 to 2010. ${ }^{4}$ As a major component of NPs, microbial-produced biopesticides have been very successful in the past, with such products as bialaphos, spinosyns, blasticidin, destruxins, bassianolide, and isarolides. ${ }^{5}$ However, after more than half a century of combinatorial chemistry research of terrestrial microorganisms, a declining number of new compounds have been found, which has prompted scientists to find new biopesticides from marine microorganisms. During the last two decades, marine-derived fungi have gained much attention among all marine organisms, as they can produce large numbers of novel biological compounds, including polyketides, meroterpenoids, terpenoids, peptides, alkaloids, and steroids, with antimicrobial, anticancer, antiviral, anti-inflammatory, antioxidant, and insecticidal activities. ${ }^{6}$ However, most of the bioactive compounds were utilized for medical, rather than agricultural applications. Hence, there is tremendous potential to find biopesticides from marine-derived fungi.

During our previous study of the agricultural applications of marine-derived fungi, 24 out of 31 fungal strains displayed obvious anti-phytopathogenic activities, and four bioactive compounds were isolated from two fungal strains. ${ }^{7}$ Due to the potential applications of marine-derived fungi for plant protection which few groups focused on, it is necessary to continue studying marine-derived fungi and their secondary metabolites that have agricultural bioactivities. In the present study, the isolation, identification, and bioactivity screening 
(phytotoxic and anti-phytopathogenic activities) of marinederived fungi are reported, and the structure elucidation, as well as biological activities of isolated compounds from one selected strain are presented and discussed.

\section{Results and discussion}

\subsection{Diversity of the isolated marine-derived fungi}

Marine fungal strains have been obtained from nearly every possible marine habitat, including marine plants (most notably algae and mangrove plants), marine invertebrates (e.g., sponges, corals, ascidians, holothurians, bivalves, and crustaceans), vertebrates (mainly fish), and inorganic matter (sediments and sea water). ${ }^{8}$ In this study, a total of 133 fungal strains were isolated from marine plants (algae and mangroves), animals (fish, crab and starfish), sediments, and seawater, which were collected from two coastal marine habitats in Qingdao and Haikou, China, in May, 2017. Among these, 88 fungal strains were from Haikou and 45 were from Qingdao. The mangrove-derived fungi were the dominant group that we obtained (59 strains), accounting for $44 \%$ in this study, followed by 37 animal-derived (28\%), 20 alga-derived (15\%), 15 sedimentderived (11\%), and two seawater-derived (2\%) strains (Fig. S1 $\dagger$ ).

It was reported that there were 530 species in 321 genera of filamentous marine fungi, among which 424 species were within Ascomycota (in 251 genera), 94 species were anamorphic fungi (in 61 genera), and 12 species were within Basidiomycota (in nine genera). These data apply to those marine taxa that can be isolated or cultivated by classical microbial techniques, and that have been studied in detail and taxonomically described by marine mycologists; the overall figures are expected to be much higher. ${ }^{8}$ Among our isolated marine-derived fungi, according to the morphotypes, strains of Penicillium sp. and Aspergillus sp. accounted for a large proportion of the 45 isolates from the Qingdao intertidal zone, while Trichoderma sp. strains seemed to be the predominant fungi of the 88 isolates from the Hainan coastal habitat. Redundant isolates were excluded by analysis of their morphological characteristics and 37 independent strains were selected for sequencing and identification according to ITS sequences. Based on the sequences deposited into the National Center for Biotechnology Information, 36 strains belonged to the phylum Ascomycota, including eight taxonomic orders: Botryosphaeriales, Diaporthales, Eurotiales, Glomerellales, Hypocreales, Mucorales, Pleosporales, and Xylariales (Fig. 1 and Table S1 $\dagger$ ). Particularly, one representative strain was grouped in the genus Poitrasia, of the order Mucorales and phylum Mucoromycota, which was the first reported Poitrasia sp. strain from marine environments. Isolates of Eurotiales (38\%), Hypocreales (27\%), and Pleosporales (16\%) were dominant. According to the phylogenetic analysis, all identified fungi belonged to 20 genera, among which Penicillium sp. (five strains), Trichoderma sp. (four strains), Talaromyces sp. (four strains), Aspergillus sp. (three strains), and Fusarium sp. (three strains) were the dominant groups, accounting for $51.4 \%$ in this study; the remaining genera occurred as singletons or doubletons.

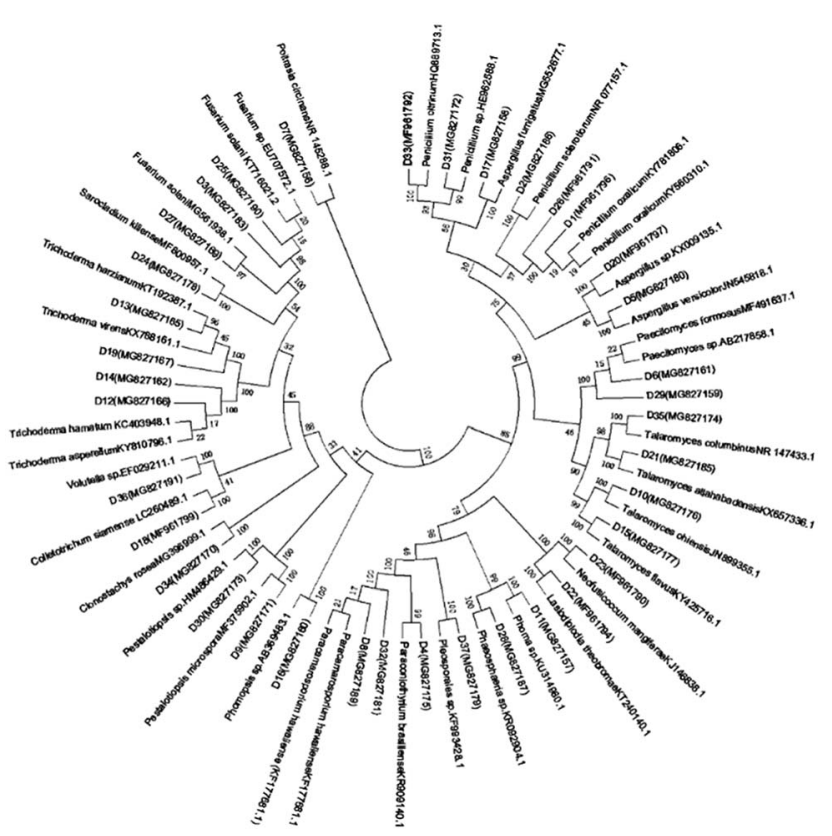

Fig. 1 Neighbor-joining phylogenetic tree of 37 representative marine-derived fungi based on $18 \mathrm{~S}$ rRNA gene sequences.

\subsection{Exploring for the bioactivities of marine-derived fungal extracts}

2.2.1 Phytotoxicity of the marine-derived fungal extracts. Natural products have had a significant impact on the development of a number of conventional pesticides. However, this has not been the case for herbicides. Although many natural products exhibit potent phytotoxicity against seed germination or germ tube elongation, ${ }^{9}$ only one class of natural productderived herbicide, the triketones, has been registered since 1997, according to the EPA. ${ }^{4}$ Marine fungi have been a hotspot for the study of new biopesticides and medicines, as they can produce secondary metabolites with novel structures and potential bioactivities. ${ }^{10}$ However, few studies have focused on their agricultural applications, especially the herbicidal effect of marine fungi. As far as we know, there has been no research studying the phytotoxicity of marine fungi and their secondary metabolites. Therefore, searching for phytotoxic compounds from marine-derived fungi holds promise.

In the present study, 37 newly isolated marine fungi and two fungal strains that we had previously obtained and showed to have potent agricultural biological activity, were tested for their phytotoxicity toward seedling growth and leaf health. The effects of the marine fungal extracts toward seedling growth of amaranth (Amaranthus retroflexus L.) and lettuce (Lactuca sativa) are shown in Table 1. Two fungal extracts (D2 and D3) significantly inhibited the seed germination of amaranth at $1.0 \mathrm{mg}$ $\mathrm{mL}^{-1}$, while no significant difference was found between the control and most of the fungal extracts for the germination of lettuce seeds. However, despite germination not being inhibited noticeably, the marine fungal isolates showed excellent inhibition of the root and hypocotyl growth of the two tested plants. Fifteen fungal extracts displayed obvious phytotoxicity toward 
Table 1 Phytotoxicity of marine fungal extracts $\left(1.0 \mathrm{mg} \mathrm{mL}^{-1}\right)$ toward seedling growth of amaranth and lettuce ${ }^{a}$

\begin{tabular}{lrllll}
\hline & \multicolumn{2}{l}{ Root length $(\mathrm{mm})$} & & \multicolumn{2}{l}{ Hypocotyl length $(\mathrm{mm})$} \\
\cline { 2 - 3 } \cline { 5 - 6 } Strains & \multicolumn{1}{l}{ Amaranth } & Lettuce & & Amaranth & Lettuce \\
\hline D1 & $6.47 \pm 0.86$ & $5.73 \pm 0.70$ & & $4.70 \pm 1.07$ & - \\
D2 & $0.00 \pm 0.00$ & - & $0.00 \pm 0.00$ & - \\
D3 & $0.00 \pm 0.00$ & - & $0.00 \pm 0.00$ & - \\
D5 & $7.55 \pm 1.24$ & - & $4.15 \pm 0.56$ & - \\
D12 & $0.00 \pm 0.00$ & - & $5.70 \pm 0.79$ & - \\
D13 & $5.15 \pm 0.34$ & $6.65 \pm 1.42$ & - & - \\
D14 & $2.30 \pm 0.27$ & $2.40 \pm 0.07$ & $4.55 \pm 1.28$ & - \\
D20 & $5.45 \pm 0.59$ & - & - & - \\
D21 & $9.10 \pm 1.00$ & - & - & - \\
D22 & $3.20 \pm 1.92$ & - & $2.15 \pm 1.46$ & - \\
D25 & $4.40 \pm 0.55$ & - & $4.50 \pm 1.42$ & - \\
D35 & $9.25 \pm 1.06$ & - & - & - \\
D36 & $8.55 \pm 1.86$ & - & - & - \\
P8 & $7.55 \pm 0.81$ & $0.00 \pm 0.00$ & $0.00 \pm 0.00$ & - \\
P18 & $10.00 \pm 1.17$ & - & $5.20 \pm 0.47$ & - \\
gp & $0.00 \pm 0.00$ & $0.00 \pm 0.00$ & $2.10 \pm 0.10$ & $4.40 \pm 0.73$ \\
ck & $22.05 \pm 1.75$ & $19.35 \pm 1.12$ & $9.45 \pm 0.40$ & $11.11 \pm 2.39$ \\
& & & &
\end{tabular}

a "gp" was glyphosate. The length $<2.0 \mathrm{~mm}$ was regarded as no germination. "-" means no obvious effect on seedling growth.

seedling growth, among which D2, D3, D12, D14, D22, and P8 were the most effective since they showed the strongest inhibition of the root or hypocotyl growth of at least one of the two tested plants. It was obvious that the effect of the marine fungal isolates on seedling growth was greater with amaranth than with lettuce, and the phytotoxicity was stronger toward root growth than toward hypocotyl growth. The genera Trichoderma was the most effective fungi as all three strains (D12, D13, and D14) showed potent phytotoxicity toward radicle and embryonal elongations. It is well-known that fungi such as Alternaria sp., Fusarium sp., and Colletotrichum sp. can produce phytotoxins that have considerable potential as models to develop herbicides with new modes of action unrelated to those in current use. Trichoderma spp. have been studied as biopesticides and biofertilizers due to their abilities to protect crops from plant pathogens and promote vegetative growth. However, products for weed control from Trichoderma spp. are commercially limited and the few known studies in this area are restricted to T. virens. ${ }^{11}$ Therefore, our report provides a new area for the application of Trichoderma sp. in agriculture.

The leaf spray experiments were performed on amaranth and Chinese pennisetum (Pennisetum alopecuroides (L.) Spreng.) in pot assays. The development of necrotic lesions after 3-7 days of treatment with 39 marine fungal extracts indicated that 10 strains showed obvious phytotoxicity toward amaranth, while six ones were effective on Chinese pennisetum (Table 2). It is notable that D5 and P8 showed phytotoxicity toward amaranth leaves that was as strong as the positive control glyphosate, and D5 still showed phytotoxicity when its concentration was decreased to $1.0 \mathrm{mg} \mathrm{mL}^{-1}$ (Fig. 2). Of importance, the phytotoxicity manifested within three days, which was faster than that of glyphosate, indicating that these fungi could produce
Table 2 Phytotoxicity of marine fungal extracts $\left(10.0 \mathrm{mg} \mathrm{mL}^{-1}\right.$ ) toward amaranth and Chinese pennisetum by leaf spray assays ${ }^{a}$

\begin{tabular}{lll}
\hline & & $\begin{array}{l}\text { Chinese } \\
\text { pennisetum }\end{array}$ \\
\hline D1 & Amaranth & \\
D3 & 2 & 0 \\
D5 & 1 & 0 \\
D6 & 4 & 0 \\
D7 & 1 & 2 \\
D10 & 1 & 1 \\
D13 & 2 & 1 \\
D17 & 1 & 0 \\
D20 & 0 & 1 \\
P8 & 3 & 3 \\
P18 & 4 & 3 \\
gP & 3 & 0 \\
\end{tabular}

${ }^{a} 0$ means no effect (control), 1 was inhibition rate $<50 \%, 2$ was $50 \%<$ inhibition rate $<70 \%$, 3 was $70 \%<$ inhibition rate $<90 \%$, and 4 was inhibition rate $>90 \%$.

secondary metabolites with potent phytotoxicity. Amaranth was much more sensitive to the marine fungal extracts than was Chinese pennisetum, and the newer leaves were more sensitive than the older ones were. Further investigation on the phytotoxicity toward amaranth and Chinese pennisetum leaves was carried out by leaf puncture assays at a low concentration of $1.0 \mathrm{mg} \mathrm{mL} \mathrm{mL}^{-1}$. Only one fungal isolate (D5) induced necrotic lesions on amaranth at $20 \mu \mathrm{g}$ per droplet 3 days after its application, demonstrating great potential of being developed as a bioherbicide (Fig. 2).

From the results above, it was obvious that seven fungal strains (D1, D3, D5, D13, D20, P8, and P18) showed phytotoxicity against not only seedling growth, but also leaf health. To the best of our knowledge, we are exploring the phytotoxicity of marine-derived fungi and the genera Poitrasia, Talaromyces, and Volutella for the first time.

2.2.2 Antifungal activity of the marine-derived fungal extracts. The 37 fungal isolates and two previously obtained fungal strains (P8 and P18) were tested for their antifungal

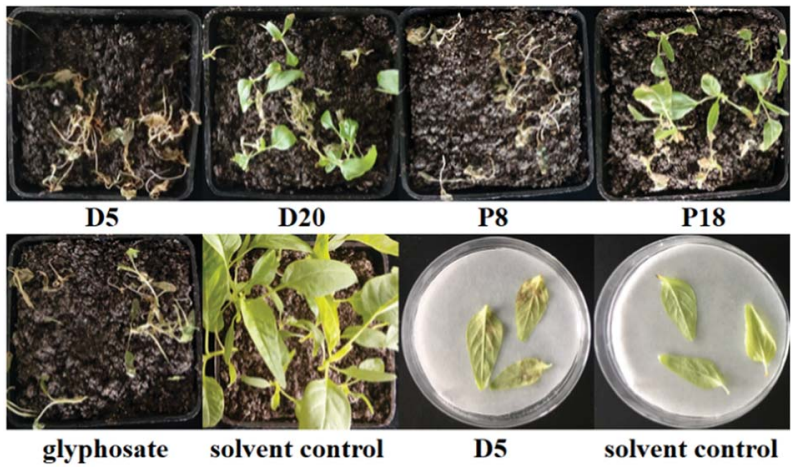

Fig. 2 Phytotoxicity of four marine-derived fungal extracts D5, D20, P8, and P18 (10.0 mg mL $\mathrm{mL}^{-1}, 5 \mathrm{~mL}$ per pot) on amaranth by leaf spray assays, and D5 $\left(1.0 \mathrm{mg} \mathrm{mL}^{-1}, 20 \mu \mathrm{L}\right)$ on amaranth by leaf puncture assays. 
activity by observing their ability to inhibit spore germination and mycelial growth of Alternaria alternata (Fries) Keissler, A. brassicicola, Aspergillus niger van. Tiegh, Diaporthe medusaea Nitschke, and Pestalotia theae. Of the 39 fungal extracts assayed, nine $(23.1 \%)$ showed antifungal activity against spore germination, while $10(25.6 \%)$ showed good inhibition $(>50 \%)$ at $10.0 \mathrm{mg} \mathrm{mL}{ }^{-1}$ against mycelial growth of at least one of the phytopathogenic fungi tested (Tables S2, S3, $\uparrow$ and Fig. 3). It should be noted that nearly all of the fungal isolates could inhibit the mycelial growth of at least one phytopathogenic fungus to varying degrees, but only the isolates with greater than $50 \%$ inhibition were considered bioactive. In general, the marine fungal extracts were most active against $A$. brassicicola and $D$. medusaea when considering both mycelium growth and spore inhibition. Fungi classified within the genera of Penicillium and Trichoderma contributed the greatest to the antifungal activity, as three strains (D1, D2, and D26) out of five Penicillium sp. and three (D12, D13, and D14) out of four Trichoderma sp. displayed obvious antifungal activity. D12, D14, and D27 exhibited the most distinct antifungal activity as they could inhibit the spore germination or mycelial growth of at least five phytopathogenic fungi, suggesting that these strains could produce interesting and useful antifungal compounds.

2.2.3 Antibacterial activity of the marine-derived fungal extracts. Marine fungal sources have been very prolific producers of thousands of natural antibiotics. More than half of all antibiotics are produced by actinomycetes, $10-15 \%$ by nonfilamentous bacteria, and $\sim 20 \%$ by filamentous fungi. ${ }^{12}$ In this study, the 37 fungal extracts (the other two ones P8 and P18 have been tested before) of the fermented fungi were evaluated for their activity against the plant bacterial pathogens, Acidovorax avenae, Pseudomonas syringae pv. lachrymans, and

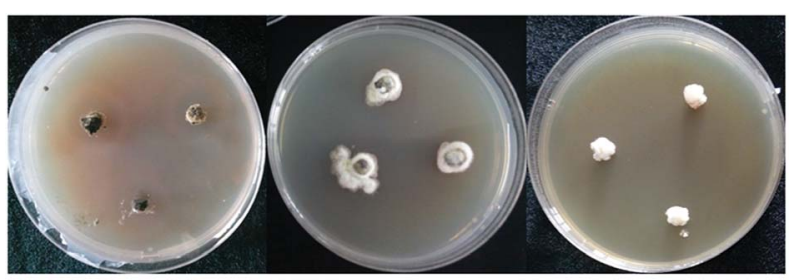

a

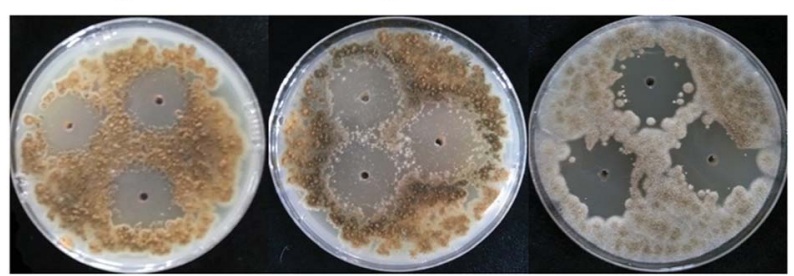

d

e

f
Fig. 3 Antifungal activity of marine-derived fungal extracts $(10.0 \mathrm{mg}$ $\mathrm{mL}^{-1}$ ). (a) Extracts of D1 against $A$. brassicicola by mycelium growth rate method; (b) extracts of D1 against $A$. alternata by mycelium growth rate method; (c) extracts of D12 against $D$. medusaea by mycelium growth rate method; (d) extracts of D26 against $A$. brassicicola by agar diffusion method; (e) extracts of D27 against $A$. brassicicola by agar diffusion method; (f) extracts of D27 against $P$. theae by agar diffusion method.
Ralstonia solanacearum. Fourteen fungi showed varying degrees of antibacterial activity at $10.0 \mathrm{mg} \mathrm{mL}^{-1}$, representing $37.9 \%$ of the fermented strains (Table $\mathrm{S} 4 \dagger$ ), while only three strains exhibited prominent activity when the test concentration was reduced to $1.0 \mathrm{mg} \mathrm{mL}{ }^{-1}$ (Fig. 4). The antibacterial activity toward the target bacterial strain, $P$. syringae pv. lachrymans, was the most remakable, which was consistent with our previous study. ${ }^{7}$ D1 and D21 were the most effective fungi and their extracts exhibited distinct antibacterial activity against both $P$. syringae pv. lachrymans and A. avenae, which was much stronger than that of the positive control, streptomycin sulfate. It was reported previously that the dominant genera in antimicrobial compound-producing marine fungi were the Aspergillus sp. and Penicillium sp, ${ }^{13}$ and our present study supported that conclusion. In particular, this was the first report of the antibacterial activity of the Poitrasia sp. fungi, to the best of our knowledge. Our study shows that continuing investigations into these marine-derived fungi represent promising strategies to identify molecules with potent antibacterial activity.

\subsection{Investigation of the bioactive compounds from Alternaria sp. 88}

We previously reported the antibacterial activity of a marinederived fungus Alternaria sp. P8 and its two bioactive secondary metabolites. ${ }^{7}$ In the present study, the potent phytotoxicity and antifungal activity of this fungus were also discovered. This suggests a broad agricultural bioactivity spectrum of P8, which warranted further investigation. Fifty Erlenmeyer flasks of fungi were cultivated in solid medium. Chemical investigations of the P8 extracts led to the isolation of one new benzopyranone, $(+)-(2 S, 3 R, 4 \mathrm{a} R)$-altenuene (1), and seven known compounds, (+)-isoaltenuene (2), ${ }^{14}$ alternariol (3), ${ }^{15}$ altenuisol $(4),{ }^{16}$ alternariol 9-methyl ether $(5),{ }^{15}$ altertoxin I (6), ${ }^{17}$ stemphyperylenol (7), ${ }^{7}$ and alterperylenol (8) (Fig. 5). ${ }^{7}$

Compound 1 was isolated as a white, amorphous powder and assigned the molecular formula $\mathrm{C}_{15} \mathrm{H}_{16} \mathrm{O}_{6}$ by HRESIMS, indicating seven degrees of unsaturation. The ${ }^{1} \mathrm{H}$ NMR spectrum displayed signals for three aromatic or olefinic protons at $\delta_{\mathrm{H}} 6.75(\mathrm{~d}, J=2.0 \mathrm{~Hz}), 6.50(\mathrm{~d}, J=2.0 \mathrm{~Hz})$, and $6.30(\mathrm{~d}, J=3.5$ $\mathrm{Hz})$; two oxymethines at $\delta_{\mathrm{H}} 3.95(\mathrm{t}, J=3.5 \mathrm{~Hz})$ and $3.70(\mathrm{dt}, J=$ $7.5,3.5 \mathrm{~Hz})$; one methoxy group at $\delta_{\mathrm{H}} 3.86(\mathrm{~s})$; one set of nonequivalent methylene protons at $\delta_{\mathrm{H}} 2.26(\mathrm{dd}, J=14.0,3.5$ $\mathrm{Hz}$ ) and $1.95(\mathrm{dd}, J=14.0,7.5 \mathrm{~Hz})$; and one methyl group at $\delta_{\mathrm{H}}$ $1.47(\mathrm{~s})$. The ${ }^{13} \mathrm{C}$ NMR and distortion less enhancement by

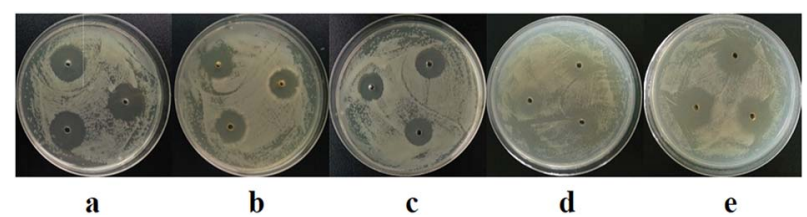

Fig. 4 Antibacterial activity of marine-derived fungal extracts $(10.0 \mathrm{mg}$ $\mathrm{mL}^{-1}$ ). (a) Extracts of $\mathrm{D} 1$ against $P$. syringae pv. lachrymans; (b) extracts of D21 against $P$. syringae pv. lachrymans; (c) extracts of D26 against $P$. syringae pv. lachrymans; (d) extracts of D1 against $A$. avenae; (e) extracts of $\mathrm{D} 21$ against $A$. avenae. 

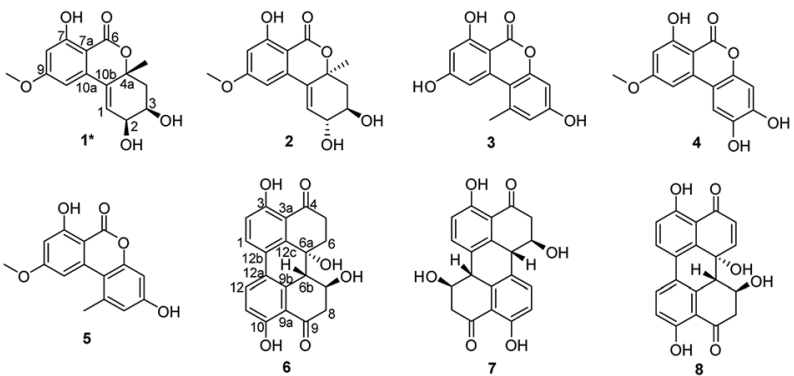

Fig. 5 Chemical structures of compounds 1-8.

polarization transfer (DEPT) spectra showed resonances for one ester carbonyl $\left(\delta_{\mathrm{C}}\right.$ 168.2), eight aromatic or olefinic carbon atoms $\left(\delta_{\mathrm{C}} 165.8,163.0,139.2,131.8,131.0,102.3,100.9\right.$, and $100.0)$, one $\mathrm{sp}^{3}$ oxygenated quaternary carbon $\left(\delta_{\mathrm{C}} 81.2\right)$, two oxymethines $\left(\delta_{\mathrm{C}} 69.5\right.$ and 68.8$)$, one methoxyl group $\left(\delta_{\mathrm{C}} 55.8\right)$, one methylene $\left(\delta_{\mathrm{C}} 38.5\right)$ and one methyl group $\left(\delta_{\mathrm{C}} 27.4\right)$. These spectroscopic features, in addition to the $2 \mathrm{D}$ NMR data, suggested that $\mathbf{1}$ belonged to the benzopyranone family and is very similar to altenuene, which was isolated from an endolichenic fungal strain, Nigrospora sphaerica (No. 83-1-1-2), cultured from tissues of the lichen, Parmelinella wallichiana (Taylor) Elix \& Hale collected from the Zixi Mountains of the Yunnan Province of China. ${ }^{\mathbf{1 4}}$

The relative configuration of $\mathbf{1}$ was deduced by $J$-based configurational analysis and 1D nuclear Overhauser effect (NOE) correlations. The ${ }^{1} \mathrm{H}-{ }^{1} \mathrm{H}$ coupling constants of $\mathrm{H}-2\left(\delta_{\mathrm{H}}\right.$ $3.95, \mathrm{t}, J=3.5 \mathrm{~Hz})$ and $\mathrm{H}-3\left(\delta_{\mathrm{H}} 3.69, \mathrm{dt}, J=7.5,3.5 \mathrm{~Hz}\right)$ indicated a cis-relationship of these two protons. The signal for Ha-4 $\left(\delta_{\mathrm{H}}\right.$ 1.95) showed one vicinal coupling constant $(J=7.5 \mathrm{~Hz})$ characteristic of axial-axial-type coupling, leading to the assignment of an axial orientation for $\mathrm{Ha}-4$ and $\mathrm{H}-3$. In the NOE difference spectrum, irradiation of $4 \mathrm{a}-\mathrm{CH}_{3}$ enhanced the resonance of Ha4 , indicating a cis relationship between them. This evidence suggested that $4 \mathrm{a}-\mathrm{CH}_{3}$ and $\mathrm{H}-2 / \mathrm{H}-3$ were on the opposite face of the molecule. The absolute configuration of $\mathbf{1}$ was determined by ECD analysis. The negative first Cotton effect at $279 \mathrm{~nm}(\Delta \varepsilon$ $-41.95)$ and the positive second one at $232 \mathrm{~nm}(\Delta \varepsilon+71.88)$ (Fig. 6) in the ECD spectrum indicated a $4 \mathrm{a} R$-configuration. ${ }^{\mathbf{1 4}}$ Thus, the absolute configuration of $\mathbf{1}$ was determined to be $2 S, 3 R, 4 \mathrm{a} R$.

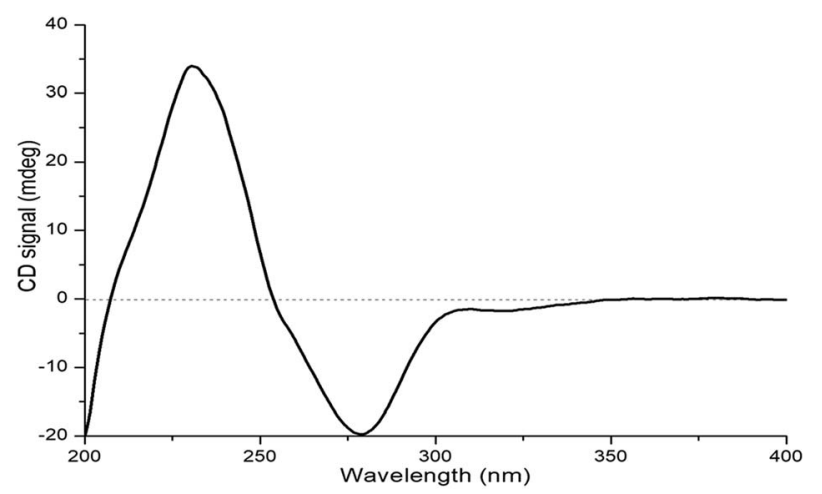

Fig. 6 ECD spectrum of compound 1.
In our previous study, we found that compound $\mathbf{8}$ exhibited potent antibacterial activity against Clavibacter michiganensis and 7 displayed obvious antifungal activity against $A$. brassicicola and $P$. theae. In the present study, the phytotoxicity of 1-8, and the antifungal and antibacterial activities of 1-6 were determined. Compounds 1, 2, and 6-8 showed obvious phytotoxicity against the seedling growth of amaranth and lettuce at 200 ppm (Table 3). The perylenequinones (6-8) were more bioactive than the benzopyranones ( 1 and 2 ) were, since they could inhibit seed germination at $200 \mathrm{ppm}$ and still display strong phytotoxicity when their concentration decreased to 50 ppm (Table 4). It seemed that the isolated compounds inhibited the seedling growth of lettuce less than that of amaranth, and their effects on root elongation were much more obvious than their effects on hypocotyl elongation. Because no phytotoxicity of 3-5 was observed, preliminary analysis of the structure-activity relationships of the benzopyranones (1-5) indicated that the replacement of benzene by cyclohexene could positively influence phytotoxicity. Compound $\mathbf{1}$ also showed potent antifungal activity toward A. brassicicola, with a minimum inhibitory concentration (MIC) of $125 \mu \mathrm{g} \mathrm{mL} \mathrm{m}^{-1}$, which was equivalent to that of the positive control carbendazim. Compound $\mathbf{6}$ displayed moderate antifungal activity against D. medusaea, with an MIC of $62.5 \mu \mathrm{g} \mathrm{mL}{ }^{-1}$, compared to $31.3 \mu \mathrm{g} \mathrm{mL}{ }^{-1}$ for carbendazim. Compounds 1-6 exhibited no obvious antibacterial activity.

\section{Experimental section}

\subsection{Fungal materials, isolation, identification, and fermentation}

The marine-derived fungi in this study were isolated from seawater, sediments, animals, and algae collected from coastal marine habitats of the Yellow Sea, Qingdao, and South China Sea, Haikou, China, during May, 2017. These samples were immediately processed for isolation and purification of fungi, using potato dextrose agar (PDA) culture media with a salinity of $3 \%$, according to the method we previously described. ${ }^{7}$ The isolated fungi were transferred into cryogenic vials containing potato dextrose water (PDW) culture media and glycerol $(\mathrm{v} / \mathrm{v}=$ $3: 1$ ), and were deposited at the Marine Agriculture Research

Table 3 Phytotoxicity of compounds 1, 2, and 6-8 (200 ppm) toward seedling growth ${ }^{a}$

\begin{tabular}{|c|c|c|c|c|}
\hline \multirow[b]{2}{*}{ Strains } & \multicolumn{2}{|c|}{ Root length (mm) } & \multicolumn{2}{|c|}{ Hypocotyl length (mm) } \\
\hline & Amaranth & Lettuce & Amaranth & Lettuce \\
\hline 1 & $4.65 \pm 0.53$ & $19.30 \pm 3.06$ & $4.96 \pm 0.45$ & $6.65 \pm 1.14$ \\
\hline 2 & $4.30 \pm 0.10$ & $14.01 \pm 1.77$ & $7.42 \pm 0.27$ & $7.78 \pm 0.87$ \\
\hline 6 & $0.00 \pm 0.00$ & $0.00 \pm 0.00$ & $0.00 \pm 0.00$ & $0.00 \pm 0.00$ \\
\hline 7 & $0.00 \pm 0.00$ & $0.00 \pm 0.00$ & $0.00 \pm 0.00$ & $0.00 \pm 0.00$ \\
\hline 8 & $0.00 \pm 0.00$ & $4.45 \pm 0.43$ & $0.00 \pm 0.00$ & $4.60 \pm 0.34$ \\
\hline gp & $0.00 \pm 0.00$ & $0.00 \pm 0.00$ & $0.00 \pm 0.00$ & $0.00 \pm 0.00$ \\
\hline $\mathrm{H}_{2} \mathrm{O}$ & $12.08 \pm 0.43$ & $21.00 \pm 1.07$ & $7.34 \pm 0.26$ & $9.00 \pm 0.54$ \\
\hline
\end{tabular}


Table 4 Phytotoxicity of compounds 1, 2, and 6-8 (50 ppm) toward seedling growth ${ }^{a}$

\begin{tabular}{|c|c|c|c|c|}
\hline \multirow[b]{2}{*}{ Strains } & \multicolumn{2}{|c|}{ Root length (mm) } & \multicolumn{2}{|c|}{ Hypocotyl length (mm) } \\
\hline & Amaranth & Lettuce & Amaranth & Lettuce \\
\hline 6 & $0.00 \pm 0.00$ & $0.00 \pm 0.00$ & $4.15 \pm 0.19$ & $0.00 \pm 0.00$ \\
\hline 7 & $0.00 \pm 0.00$ & $2.25 \pm 0.26$ & $4.90 \pm 0.45$ & $3.45 \pm 0.26$ \\
\hline 8 & $0.00 \pm 0.00$ & $7.90 \pm 0.41$ & $6.00 \pm 0.39$ & $5.07 \pm 0.21$ \\
\hline gp & $0.00 \pm 0.00$ & $0.00 \pm 0.00$ & $0.00 \pm 0.00$ & $0.00 \pm 0.00$ \\
\hline $\mathrm{H}_{2} \mathrm{O}$ & $12.08 \pm 0.43$ & $21.00 \pm 1.07$ & $7.34 \pm 0.26$ & $9.00 \pm 0.54$ \\
\hline
\end{tabular}

Center, Tobacco Research Institute of Chinese Academy of Agricultural Sciences, Qingdao, China. The obtained fungi were identified according to morphological characteristics and a molecular protocol by amplification and DNA sequencing of the internal transcribed spacer (ITS) region of the rRNA gene, as well as phylogenetic analysis.

The separated marine-derived fungi were cultivated in PDW culture media with $3 \%$ salinity in three, $1 \mathrm{~L}$ Erlenmeyer flasks (each containing $400 \mathrm{~mL}$ of culture broth) at $28{ }^{\circ} \mathrm{C}$ without shaking for 40 days. The pooled cultures $(1.2 \mathrm{~L})$ were filtered to separate the broth from the mycelia. The mycelia were extracted three times with $\mathrm{CH}_{2} \mathrm{Cl}_{2}: \mathrm{MeOH}(1: 1, \mathrm{v} / \mathrm{v})$, and the solution was concentrated under reduced pressure to afford a residue, which was extracted with EtOAc three times. Then, the broth was extracted three times with an equal volume of EtOAc, and the mycelia extracts were combined and concentrated under vacuum to afford a total extract.

\subsection{Bioassays of the marine-derived fungal extracts}

3.2.1 Phytotoxicity assays. The phytotoxicity of the marinederived fungal isolates were assayed using seedling growth, leaf spray, and leaf puncture experiments.

In the seedling growth assays, seeds of two dicotyledons, amaranth and lettuce were used. The procedure was conducted according to a published protocol with slight modifications. ${ }^{18}$ The plant seeds were soaked in sterile water for $5 \mathrm{~h}$ and in $0.3 \%$ NaClO for $15 \mathrm{~min}$, then were rinsed three times with sterile water. The extracts were dissolved in methanol to a final concentration of $1.0 \mathrm{mg} \mathrm{mL}^{-1}$, and $200 \mu \mathrm{L}$ per well was added to 24-well plats containing filter paper at the bottom of the wells (Whatman no. 1). Glyphosate and methanol were used as a positive control and solvent control, respectively. After the methanol evaporated, five seeds were placed in each well of the 24 -well plates, and $200 \mu \mathrm{L}$ of sterile water per well was added. The plates were then incubated at $28{ }^{\circ} \mathrm{C}$ for $96 \mathrm{~h}$ with a cycle of $12 \mathrm{~h}$ light and $12 \mathrm{~h}$ dark. The lengths of the roots and hypocotyls were recorded.

The leaf spray assays were performed using the leaves of amaranth and Chinese pennisetum, according to a previously described method, with modifications. ${ }^{19}$ Plastic pots $(10 \mathrm{~cm}$ diameter) were filled with nutrient soil bought from Shouguang Wode Nursery Substrate Co. Ltd., Weifang, China. Twenty seeds were planted in each pot, and after seeding, the pots were placed in trays without drainage holes and watered from the bottom. The plants were grown in an illuminating incubator at $28{ }^{\circ} \mathrm{C}$ with $12 \mathrm{~h}$ illumination and $12 \mathrm{~h}$ darkness. Fourteen-dayold amaranth (3-4 true leaf stage) and 7 day-old Chinese pennisetum (10-12 cm high) were used for experiments. The fungal extracts were dissolved in $4 \% \mathrm{MeOH}$ with $0.25 \%$ surfactant (pesticide emulsifier 1602) to final concentrations of 10.0, 5.0, and $1.0 \mathrm{mg} \mathrm{mL} \mathrm{m}^{-1}$. Glyphosate and $4 \% \mathrm{MeOH}$ were used as a positive control and solvent control, respectively. The solutions $(5.0 \mathrm{~mL})$ were sprayed on the plants and a qualitative estimation of phytotoxicity was obtained by using a visual rating scale from 0 to 4 , where 0 was no effect (solvent control), 1 was an inhibition $<50 \%$, 2 was $50 \%<$ inhibition $<70 \%$, 3 was $70 \%<$ inhibition $<90 \%$, and 4 was inhibition $>90 \%$.

The leaf puncture assays were carried out using the leaves of amaranth and Chinese pennisetum by a previously described method. ${ }^{20}$ The fungal extracts were dissolved in $4 \% \mathrm{MeOH}$ to a final concentration of $1.0 \mathrm{mg} \mathrm{mL}^{-1}$. A droplet $(20 \mu \mathrm{L})$ of solution was applied to detached leaves previously punctured with a needle. Glyphosate and $4 \% \mathrm{MeOH}$ were used as a positive control and solvent control, respectively. The leaves were kept in a moistened chamber under continuous fluorescent lighting. Symptoms were estimated visually 3-7 days after droplet application.

3.2.2 Antifungal assays. The antifungal activity of the extracts against five plant pathogenic fungi, including A. alternata (Fries) Keissler, A. brassicicola, D. medusaea Nitschke, and $P$. theae was evaluated by the mycelium growth rate method with slight modification. ${ }^{21}$ The fungal extracts were dissolved in dimethyl sulfoxide (DMSO) to generate a final concentration of $10.0 \mathrm{mg} \mathrm{mL}^{-1}$, and $100 \mu \mathrm{L}$ was then spread on each Petri dish (diameter $=9 \mathrm{~cm})$ containing $20 \mathrm{~mL}$ PDA media. A mycelial agar disk (diameter $=4 \mathrm{~mm}$ ) of each plant pathogenic fungus from the edge of $72 \mathrm{~h}$-old culture was placed in the center of the Petri dish. The dish was incubated at $28{ }^{\circ} \mathrm{C}$ for $72 \mathrm{~h}$. Prochloraz and DMSO were employed as a positive control and solvent control, respectively. Then, the diameter of each colony was measured by making two measurements at right angles. The inhibitions of growth were calculated using the following formula, where $D$ represents the average colony diameter of the tested extracts, $D_{\text {ck }}$ represents the average colony diameter of the solvent control, and 4 is the diameter of the original mycelial agar disk (in $\mathrm{mm}$ ).

Inhibition of growth $(\%)=\left[1-(D-4) /\left(D_{\mathrm{ck}}-4\right)\right] \times 100$

The antifungal activity of the EtOAc extracts against the plant pathogenic fungi, A. alternata (Fries) Keissler, A. brassicicola, A. niger van. Tiegh, and $P$. theae, was also tested using an agar diffusion method, with modifications. ${ }^{22}$ Briefly, the spores of the fungi were adjusted to $1 \times 10^{5} \mathrm{CFU} \mathrm{mL} \mathrm{m}^{-1}$, and $100 \mu \mathrm{L}$ suspensions were then spread on Petri dishes (diameter $=9 \mathrm{~cm}$ ) containing $20 \mathrm{~mL}$ PDA media. Three wells (diameter $=6 \mathrm{~mm}$ each) were created in this pathogen-embedded agar with sterile glass tubes. The lyophilized EtOAc extracts were dissolved in 
DMSO to a final concentration of $10.0 \mathrm{mg} \mathrm{mL}^{-1}$ and $10 \mu \mathrm{L}$ of the solutions was added to each well on the plates. Prochloraz and DMSO were employed as a positive control and solvent control, respectively. The Petri dishes were incubated at $28^{\circ} \mathrm{C}$ for $72 \mathrm{~h}$ in darkness and the diameter of each zone of inhibition was measured.

3.2.3 Antibacterial assays. The antibacterial activity of the EtOAc extracts against three plant pathogenic bacteria, namely $A$. avenae, $P$. syringae pv. lachrymans, and $R$. solanacearum, was evaluated by an agar diffusion method that previously reported. ${ }^{7,23}$

\subsection{Isolation and structure elucidation of compounds from Alternaria sp. $\mathbf{P 8}$}

Optical rotations were measured on a Jasco P-1020 digital polarimeter (Jasco, Inc., Easton, MD, USA), and UV spectra were recorded on a Techcomp UV2310II spectrophotometer (Techcomp, Ltd., Shanghai, China). Electronic circular dichroism (ECD) spectra were obtained on a Jasco J-815-150S circular dichroism spectrometer (Jasco, Inc., Tokyo, Japan). NMR spectra were recorded on an Agilent DD2 $500 \mathrm{MHz}$ NMR spectrometer $\left(500 \mathrm{MHz}\right.$ for ${ }^{1} \mathrm{H}$ and $125 \mathrm{MHz}$ for ${ }^{13} \mathrm{C}$; Agilent Technologies, Santa Clara, CA, USA) using tetramethylsilane as an internal standard. Electrospray ionization mass spectrometry (ESIMS) and high-resolution electrospray ionization mass spectrometry (HRESIMS) spectra were obtained with a Micromass Q-TOF spectrometer and Thermo Scientific LTQ Orbitrap XL spectrometer. Semi-preparative HPLC was performed on a Waters C18 $(5 \mu \mathrm{m}, 10 \times 250 \mathrm{~mm})$ column using a Waters 2695 separation module equipped with a Waters 2996 photodiode array (PDA) detector (Waters, MA, USA). Silica gel (200-300 mesh; Qing Dao Hai Yang Chemical Group Co., Qingdao, China), octadecylsilyl-silica gel (45-60 $\mu \mathrm{m}$; Merck, Darmstadt, Germany), and Sephadex LH-20 (GE Healthcare, Uppsala, Sweden) were used for column chromatography. Compounds were monitored by thin layer chromatography (TLC) (G60, F-254; Yan Tai Zi Fu Chemical Group Co., Yantai, China), and spots were visualized by heating the silica gel plates after spraying with $12 \% \mathrm{H}_{2} \mathrm{SO}_{4}$ in $\mathrm{H}_{2} \mathrm{O}$ containing saturated vanillins.

The fungal strain Alternaria sp. P8 was fermented on rice media in 50 Erlenmeyer flasks (each containing $80 \mathrm{~g}$ rice and $120 \mathrm{~mL} \mathrm{H}_{2} \mathrm{O}$ ) at $28{ }^{\circ} \mathrm{C}$ for 40 days. The culture medium was extracted three times with $\mathrm{CH}_{2} \mathrm{Cl}_{2}: \mathrm{MeOH}(1: 1, \mathrm{v} / \mathrm{v})$, and the pooled solutions were concentrated under reduced pressure to afford a residue, which was extracted with EtOAc three times. The pooled EtOAc extracts were concentrated under reduced pressure and subjected to vacuum liquid chromatography (VLC) on silica gel. An eluent gradient of EtOAc in petroleum ether $(0 /$ 100 to $100 / 0, v / v)$ followed by $\mathrm{MeOH}$ in EtOAc $(0-100 \%)$ was used to give five fractions (Fr. 1-Fr. 5). Fr. 3 was first subjected to silica gel column chromatography (mobile phase, $30 \%$ EtOAc in petroleum ether), and then separated by octadecyl-silica column, eluting with $30-60 \% \mathrm{MeOH}$ in $\mathrm{H}_{2} \mathrm{O}$, to obtain Fr. 31-Fr. 3-3. Fr. 3-2 was applied to Sephadex LH-20 column chromatography (mobile phase, $\mathrm{CH}_{2} \mathrm{Cl}_{2}: \mathrm{MeOH}, 1: 1$, v/v), followed by purification on HPLC with $60 \% \mathrm{MeOH}$ to afford $5(8.9 \mathrm{mg})$.
Fr. 4 was fractionated on silica gel column chromatography using a gradient elution with petroleum ether : EtOAc to afford three subfractions (Fr. 4-1-Fr. 4-4). Fr. 4-3 was applied to an octadecyl-silica column, eluting with $50 \% \mathrm{MeOH}$ and then was purified by Sephadex LH-20 column chromatography (mobile phase, $\mathrm{CH}_{2} \mathrm{Cl}_{2}: \mathrm{MeOH}, 1: 1, \mathrm{v} / \mathrm{v}$ ) to obtain three subfractions (Fr. 4-3-1-4-3-3). Fr. 4-3-2 was purified on HPLC with 25\% MeCN in $\mathrm{H}_{2} \mathrm{O}$ to give $6(15.3 \mathrm{mg}), 7(8.5 \mathrm{mg})$, and $8(11.2 \mathrm{mg})$, while $\mathrm{Fr}$. 4-3-3 was purified by semipreparative HPLC, eluting with $50 \%$ $\mathrm{MeOH}$ to give $3(14.6 \mathrm{mg})$ and $4(5.1 \mathrm{mg})$. Fr. $4-4$ was purified on HPLC with $35 \%$ MeCN to give $1(17.2 \mathrm{mg})$ and $2(18.9 \mathrm{mg})$.

$(+)-(2 S, 3 R, 4 \mathrm{a} R)$-Altenuene (1): white, amorphous powder; $[\alpha]_{\mathrm{D}}^{20}-6.4^{\circ}(c 0.10, \mathrm{MeOH}) ; \mathrm{UV}(\mathrm{MeOH}) \lambda_{\max }(\log \varepsilon) 240(4.80)$, 278 (4.33), 319 (4.10) nm; ECD (0.14 mM, MeOH) $\lambda_{\max }(\Delta \varepsilon) 232$ $(+71.88), 279(-41.95) \mathrm{nm} ;{ }^{1} \mathrm{H}$ NMR (DMSO- $\left.d_{6}, 500 \mathrm{MHz}\right) \delta 11.30$ $(\mathrm{s}, 7-\mathrm{OH}), 6.75(1 \mathrm{H}, \mathrm{d}, J=2.0 \mathrm{~Hz}, \mathrm{H}-10), 6.54(1 \mathrm{H}, \mathrm{d}, J=2.0 \mathrm{~Hz}$, $\mathrm{H}-8), 6.30(1 \mathrm{H}, \mathrm{d}, J=3.5 \mathrm{~Hz}, \mathrm{H}-1), 3.95(1 \mathrm{H}, \mathrm{t}, J=3.5 \mathrm{~Hz}, \mathrm{H}-2)$, $3.86\left(3 \mathrm{H}, \mathrm{s}, 9-\mathrm{OCH}_{3}\right), 3.69(1 \mathrm{H}, \mathrm{dt}, J=7.5,3.5 \mathrm{~Hz}, \mathrm{H}-3), 2.26(1 \mathrm{H}$, $\mathrm{dd}, J=14.0,3.5 \mathrm{~Hz}, \mathrm{He}-4), 3.69(1 \mathrm{H}, \mathrm{dt}, J=7.5,3.5 \mathrm{~Hz}, \mathrm{H}-3), 1.95$ $(1 \mathrm{H}, \mathrm{dd}, J=14.0,7.5 \mathrm{~Hz}, \mathrm{Ha}-4), 1.47(1 \mathrm{H}, \mathrm{s}, J=14.0,7.5 \mathrm{~Hz}, 4 \mathrm{a}-$ $\left.\mathrm{CH}_{3}\right) ;{ }^{13} \mathrm{C}$ NMR (DMSO- $\left.d_{6}, 125 \mathrm{MHz}\right) \delta 168.2$ (C, C-6), 165.8 (C, C9), 163.0 (C, C-7), 139.2 (C, C-10a), 131.8 (C, C-10b), 131.0 (CH, C-1), 102.3 (CH, C-10), 100.9 (CH, C-8), 100.0 (C, C-7a), 81.2 (C, $\mathrm{C}-4 \mathrm{a}), 69.5(\mathrm{CH}, \mathrm{C}-2), 68.8(\mathrm{CH}, \mathrm{C}-3), 55.9\left(\mathrm{CH}_{3}, 9-\mathrm{OCH}_{3}\right), 38.5$ $\left(\mathrm{CH}_{2}, \mathrm{C}-4\right), 27.4\left(\mathrm{CH}_{3}, 4 \mathrm{a}-\mathrm{CH}_{3}\right)$; HRESIMS $m / z 291.0878[\mathrm{M}-\mathrm{H}]^{-}$ (calcd for $\mathrm{C}_{15} \mathrm{H}_{15} \mathrm{O}_{6}, 291.0874$ ).

\subsection{Bioassays of compounds 1-8}

The phytotoxicity of 1-8 against seed germination and seedling growth of amaranth and lettuce (200 and $50 \mathrm{ppm}$ ) was conducted as mentioned above. The antibacterial and antifungal activities were evaluated by a conventional broth-dilution assay according to the National Center for Clinical Laboratory Standards recommendations, with modifications as we previously reported. ${ }^{7}$

\section{Conclusions}

In summary, 37 marine-derived fungi were identified from 133 strains that were isolated from several marine biotopes. The diversity of the obtained fungi was investigated, leading to the discovery of the first marine-derived Poitrasia sp. strain. The phytotoxicity, as well as the anti-phytopathogenic fungal and bacterial activities of the fungal extracts were tested, and one strain, Alternaria sp. P8, was selected for chemical investigation according to its bioactivity. This resulted in the isolation of eight compounds, including one new compound, which exhibited potent phytotoxicity, antifungal activity, and antibacterial activity. The phytotoxicity of marine-derived fungi in this study is very interesting, since this is the first report, to the best of our knowledge, on the discovery and evaluation of the phytotoxic efficacy of marine-derived fungi. As few studies focus on agricultural bioactivities, our results suggest that exploring the application of marine-derived fungi in agriculture represents a promising strategy for discovering new biopesticides. 


\section{Conflicts of interest}

There are no conflicts to declare.

\section{Acknowledgements}

This work was supported by the National Natural Science Foundation of China (41806194), the Fundamental Research Funds for Central Non-profit Scientific Institution (1610232017013), and the Science Foundation for Young Scholars of Tobacco Research Institute of Chinese Academy of Agricultural Sciences (2017B08).

\section{Notes and references}

1 C. Buttimer, O. Mcauliffe, R. P. Ross, C. Hill, J. O'Mahony and A. Coffey, Front. Microbiol., 2017, 8, 34.

2 S. Mostafalou and M. Abdollahi, Arch. Toxicol., 2016, 91, 151.

3 J. N. Seiber, J. Coats, S. O. Duke and A. D. Gross, J. Agric. Food Chem., 2014, 62, 11613-11619.

4 C. L. Cantrell, F. E. Dayan and S. O. Duke, J. Nat. Prod., 2012, 75, 1231-1242.

5 S. Saxena, Allelopathy J., 2014, 33, 1-24.

6 J. W. Blunt, A. R. Carroll, B. R. Copp, R. A. Davis, R. A. Keyzers and M. R. Prinsep, Nat. Prod. Rep., 2018, 35, 8-53.

7 D. L. Zhao, D. Wang, X. Y. Tian, F. Cao, Y. Q. Li and C. S. Zhang, Mar. Drugs, 2018, 16, 36.

8 M. E. Rateb and R. Ebel, Nat. Prod. Rep., 2011, 28, 290-344.
9 M. Vurro, A. Boari, A. Evidente, A. Andolfi and N. Zermane, Pest Manage. Sci., 2010, 65, 566-571.

10 J. F. Imhoff, Mar. Drugs, 2016, 14, 19.

11 A. Javaid and S. Ali, Nat. Prod. Res., 2011, 25, 730-740.

12 S. Johanna, K. Annemarie, L. Antje and T. Deniz, Mar. Drugs, 2016, 14, 137.

13 L. Xu, W. Meng, C. Cao, J. Wang, W. Shan and Q. Wang, Mar. Drugs, 2015, 13, 3479-3513.

14 J. W. He, G. D. Chen, H. Gao, F. Yang, X. X. Li, T. Peng, L. D. Guo and X. S. Yao, Fitoterapia, 2012, 83, 1087-1091.

15 W. Gu, World J. Microbiol. Biotechnol., 2009, 25, 1677-1683.

16 N. Kim, M. J. Sohn, H. Koshino, E. H. Kim and W. G. Kim, Bioorg. Med. Chem. Lett., 2014, 24, 83-86.

17 T. Okuno, I. Natsume, K. Sawai, K. Sawamura, A. Furusaki and T. Matsumoto, Tetrahedron Lett., 1983, 24, 5653-5656.

18 Q. Zhang, S. Q. Wang, H. Y. Tang, X. J. Li, L. Zhang, J. Xiao, Y. Q. Gao, A. L. Zhang and J. M. Gao, J. Agric. Food Chem., 2013, 61, 11447-11452.

19 M. G. Corral, J. Leroux, S. Tresch, T. Newton, K. A. Stubbs and J. S. Mylne, Pest Manage. Sci., 2018, 74, 1558-1563.

20 A. Cimmino, A. Andolfi, M. C. Zonno, C. Troise, A. Santini, A. Tuzi, M. Vurro, G. Ash and A. Evidente, J. Nat. Prod., 2012, 75, 1130-1137.

21 Q. Li, L. Qiu, W. Tan, G. Gu and Z. Guo, $R S C A d v .$, 2017, 7, 42225-42232.

22 C. H. Bock, D. I. Shapiro-Ilan, D. E. Wedge and C. L. Cantrell, J. Pest Sci., 2014, 87, 155-162.

23 A. Zhu, M. Y. Yang, Y. H. Zhang, C. L. Shao, C. Y. Wang, L. D. Hu, F. Cao and H. J. Zhu, Sci. Rep., 2018, 8, 10621. 